\title{
Effect of Nutrition on Oral Cancer, Review
}

\author{
Nada AL-Hajajreh ${ }^{1}$ and Ahmed Alomar ${ }^{2 *}$ \\ ${ }^{1}$ Dietitian specialist in private clinic, Saudi Arabia \\ ${ }^{2}$ Associate consultant of oral and maxillofacial surgery, King Saud University
}

*Corresponding author: Ahmed Alomar, Associate consultant of oral and maxillofacial surgery, King Saud University, Saudi Arabia.

\author{
Received Date: April 08, 2020 \\ Published Date: May 06, 2020
}

\section{Mini Review}

Oral and pharyngeal cancer, grouped together, represent the sixth most common cancer in the world1. The annual estimated incidence is around 275,000 for oral and 130,300 for pharyngeal cancers excluding nasopharynx, with two thirds of these cases occurring in developing countries [1]. Oral cancer is one of the most prevalent and the $10^{\text {th }}$ familiar cause of death. The prevalence of oral cancer is less than $3 \%$ of all cancers in the United States but it is the eight most common cancer in males and the fifteenth most common in females [2]. The role of diet in the etiology of oral and pharyngeal cancer remains unresolved. A recent revision concluded that consumption of non-starchy vegetables, fruits, and foods containing carote-noids probably protect against these cancers but available evidence is still inconsistent for other dietary components [3].The analysis of dietary patterns may help to show the influence of diet on risk of oral cancer [4]. The "traditional" pattern characterized by rice, beans and meat consumption, was inversely associated with oral cancer. Similar finding were observed in a study conducted in São Paulo and it was hypothesized that it might be due to the practice of consuming regular meals of this traditional mixture [5]. The type of carbohydrate could influence the amount of short-chain fatty acids produced, and starch has been associated with an increased production of butyrate 19 , which could induce an inhibitory effect of oral carcinoma cell proliferation [6]. Tobacco and alcohol are the major recognized risk factors for OCP cancer, with relative risks in the order of 5-10 for smokers as compared with nonsmokers (IARC, 2004) and for heavy drinkers as compared with abstainers or moderate drinkers [7].

In a metacentric case-control study from Italy and Switzerland conducted in the 1990s, the odds ratio (OR) of OCP cancer for the highest vs the lowest level of consumption was 0.4 for raw vegetables, 0.5 for cooked vegetables, 0.5 for citrus fruits and 0.7 for other fruits, and ORs were between 0.3 and 0.7 for various antioxidant vitamins, including carotene, vitamin $\mathrm{C}$ and $\mathrm{E}$, thiamine, vitamin B6, folic acid and niacin [8]. Significant inverse associations were also reported for high consumption of bread, poultry, fish, proteins and monounsaturated fats, whereas direct associations were observed for eggs, processed meat, sweets and desserts and saturated fatty acids [8]. In the present work, we analysed the role of selected food groups, macronutrients and micronutrients on OCP cancer in a case-control study carried out in Italy and Switzerland since the late 1990s [8]. According to F Bravi et al [9] their cases had a lower BMI and were more frequently heavily exposed to tobacco smoking and alcohol Drinking [9]. Insufficient calorie intake leads to malnutrition and loss of weight in patients with oral cancer [10]. Because of this, patients have more difficulty in coping with the negative impact of treatment $[11,12]$. It was well established that high consumption of fresh vegetables, fruits, fish and seafood could protect against oral cancer [13].

Researched showed that $1 / 3$ of all cancer-related deaths were caused by incorrect human behaviours such as smoking, consumption of alcohol, poor diet quality and physical inactivity [14]. It is postulated that diet has the potential to prevent up to half of OPLC incidences, based on estimates by the World Cancer Research Fund and American Institute for Cancer Research (WCRF/ AICR) (Oral, pharyngeal and laryngeal cancer (OPLC) [15]. In vivo synthesis of carcinogens caused by changes in metabolism due to altered dietary habits (i.e., indirect carcinogenesis) [16,17].Vitamin $\mathrm{C}$, or ascorbic acid, has been studied as an antioxidant agent against cancer [18].Alcohol consumption increases the risk and the development of cancer in oral cavity, pharynx, nasopharynx, laryngeal and liver [19]. There are many more foods containing antioxidant that have some benefit effects on the cancer prevention and reducing the damaging effects of oxidative stress $[20,21]$. The best fats are unsaturated fats, which come from plant sources, are 
liquid at room temperature, and decrease the cancer risk. Primary sources include olive oil, canola oil, nuts and avocados. Furthermore, we should focus on omega- 3 fatty acids, which fight inflammation and support brain and heart health. Good sources include salmon, tuna and flaxseeds [22,23].

\section{Conclusion}

Cancer is a worldwide problem and oral cancer is one of the most prevalent cancers and one of the 10th familiar causes of death with a complex etiology. Tobacco use and alcohol consumption is widely considered its major risk factors. Low beta-carotene, fruits and vegetables intakes have been associated with an increased risk of oral cancers. A low intake of vitamin $\mathrm{C}$ has been associated with an increased risk of cancers of the stomach, esophagus and oral cavity. However, balanced intake of omega 3 and 6 fats, vitamin $\mathrm{D}$ and probiotics and reduced sugar intake have been advised. Many studies showed that the use of vitamin E supplements was correlated with a diminished risk of oral and pharyngeal cancers. As reviewed above, reduction of cancer rate have been reported in studies of human diets. These reductions are depending on the factors mentioned in this review.

\section{Acknowledgment}

None.

\section{Conflict of Interest}

No conflict of interest.

\section{References}

1. Ferlay J, Pisani P, Parkin DM (2004) GLOBOCAN 2002: cancer incidence, mortality and prevalence worldwide. IARC Cancer Base (2002 estimates). Lyon: IARC Press.

2. Chi AC, Damm DD, Neville BW (2008) Oral and maxillofacial pathology: Elsevier Health Sciences.

3. World Cancer Research Fund (2007) Food, nutrition, physical activity and the prevention of cancer: a global perspective. Atlanta: World Cancer Research Fund.

4. (2010) Dietary patterns and risk of oral and pharyngeal cancer: a casecontrol study in Rio de Janeiro, Brazil Cad. Saúde Pública, Rio de Janeiro 26(1): 135-142.

5. Jané-Salas E, Chimenos-Küstner E, López-López J, Roselló-Llabrés X (2003) Importance of diet in the prevention of oral cancer. Med Oral 8: 260-268.
6. Marchioni DML, Fisberg RM, Góis Filho JF, Kowalski LP, Carvalho MB, et al. (2007) Dietary patterns and risk of oral cancer: a case-control study in Sao Paulo, Brazil. Rev Saúde Pública 41: 19- 26.

7. Bagnardi V, Blangiardo M, La Vecchia C, Corrao G (2001) A meta-analysis of alcohol drinking and cancer risk. Br J Cancer 85: 1700-1705.

8. Franceschi S, Favero A, Conti E, Talamini R, Volpe R (1999a) Food groups, oils and butter, and cancer of the oral cavity and pharynx. Br J Cancer 80: 614-620.

9. F Bravi, C Bosetti, M Filomeno, F Levi, W Garavello, et al. (2013) Foods, nutrients and the risk of oral and pharyngeal cancer, British Journal of Cancer 109: 2904-2910.

10. Jager-Wittenaar H, Dijkstra PU, Vissink A, Langendijk JA, van der Laan $\mathrm{BF}$, et al. (2011) Changes in nutritional status and dietary intake during and after head and neck cancer treatment. Head Neck 33: 863-870.

11. Bozzetti F (2010) Nutritional support in patients with oesophageal cancer. Support Care Cancer 18: S41-S50.

12. Van Bokhorst-De van der Schuer MA, von Blomberg-van der Flier BM, Riezebos RK, Scholten PE, Quak JJ, et al. (1998) Differences in immune status between well-nourished and malnourished head and neck cancer patients. Clin Nutr 17: 107-111.

13. Petridou E, Zavras AI, Lefatzis D, Dessypris N, Laskaris G, et al. (2002) The role of diet and specific micronutrients in the etiology of oral carcinoma. Cancer 94: 2981-2988.

14. Chen F, Lin T, Yan L, Liu F, Huang J, et al. (2017) Novel polymorphism in FADS1 gene and fish consumption on risk of oral cancer: A case-control study in southeast China. Oncotarget 8:15887- 15893.

15. Kushi LH, Byers T, Doyle C (2006) American Cancer Society Guidelines on Nutrition and Physical Activity for cancer preרvention: reducing the risk of cancer with healthy food choices and physical activity. CA Cancer J Clin 56: 254-228.

16. Society AC (2008) Cancer facts \& figures: The Society.

17. WCRF/AICR (2007) Food, nutrition, physical activity, and the prevention of cancer: A global perspective. Washington, DC: WCRF/AICR.

18. Key TJ, Allen NE (2002) The effect of direction risk of cancer. Lancet 360: $861-868$.

19. Wynder EL (1976) Nutrition and cancer. Fed Proc 35: 1309-1315.

20. Fletcher AE, Breeze E, Shetty PS (2003) Antioxidant vitamins and mortality in older persons: findings from the nutrition add-on study to the Medical Research Council Trial of Assessment and Management of Older People in the Community. Am J Clin Nutr 78: 999-1010.

21. Parkin D (2011) Cancers attributable to consumption of alcohol in the UK in 2010. Br J Cancer 105: S14-S18.

22. Shiva A (2015) Review article about nutrition and primary prevention of oral cancer. Rev clin med 2(3):138-143.

23. Finegold SM, Sutter VL, Sugihara PT (1977) Fecal microbial flora in Seventh Day Adventist populations and control subjects. Am J Clin Nut 30: 1781-1792. 